Article

\title{
Thermoelectric Characteristics of Silicon Carbide and Tungsten-Rhenium-Based Thin-Film Thermocouples Sensor with Protective Coating Layer by RF Magnetron Sputtering
}

\author{
Zhongkai Zhang ${ }^{1,2}$, Bian Tian ${ }^{1, *}$, Yan Liu ${ }^{1}$, Zhe Du ${ }^{1}$, Qijing Lin ${ }^{1}$ and Zhuangde Jiang ${ }^{1}$ \\ 1 State Key Laboratory for Mechanical Manufacturing Systems Engineering, Xi'an Jiaotong University, \\ Xi'an 710049, China; z.zhongkai@stu.xjtu.edu.cn (Z.Z.); liuyanzj402@stu.xjtu.edu.cn (Y.L.); \\ duzhechn@stu.xjtu.edu.cn (Z.D.); linqijingcor@163.com (Q.L.); zhuangdejiangcor@163.com (Z.J.) \\ 2 Institute of Materials in Electrical Engineering 1, RWTH Aachen University, 52074 Aachen, Germany \\ * Correspondence: t.b12@mail.xjtu.edu.cn
}

Received: 8 May 2019; Accepted: 18 June 2019; Published: 20 June 2019

\begin{abstract}
A thin-film thermocouples (TFTCs) sensor based on silicon carbide substrate, $95 \mathrm{wt} \%$ tungsten $-5 \mathrm{wt} \%$ rhenium (W-5Re) and $74 \mathrm{wt} \%$ tungsten $-26 \mathrm{wt} \%$ rhenium (W-26Re) thermosensitive part with aluminum oxide protective coating layer was designed and fabricated by radio frequency (RF) magnetron sputtering. It exhibited a high thermoelectric voltage of $35.51 \mathrm{mV}$ when the temperature difference was $1240^{\circ} \mathrm{C}$ (the hot junction temperature was $1420^{\circ} \mathrm{C}$ ), with an average Seebeck coefficient of $28.63 \mu \mathrm{V} /{ }^{\circ} \mathrm{C}$, which was $27 \%$ larger than the standard C-type thermocouple wires at the same temperature difference. The repeatability error was $\pm 4.1 \%$, the drift rate was $9.6^{\circ} \mathrm{C} / \mathrm{h}$ for $10 \mathrm{~h}$ and the laser response time was $0.36 \mathrm{~ms}$. Compared to the traditional thermocouple, it could provide long-term temperature testing within $1420^{\circ} \mathrm{C}$ for the requirement of high-temperature measurement and high response speed.
\end{abstract}

Keywords: Film; sensor; thermoelectricity

\section{Introduction}

High-temperature measurement in a narrow space, such as a combustion chamber in an engine, imposes harsh requirements for thermosensitive parts to meet [1-5]. Thin-film thermocouples (TFTCs) are suitable for in situ and real-time measurement with no airflow disturbance of the environment for its nanoscale thickness and negligible mass [6-9]. TFTCs are widely used as a new type of thermal sensor [10-12]. In the 1980s, the National Aeronautics and Space Administration (NASA) Lawrence Center had already started research into TFTCs for turbine blade surface temperature measurements and successfully deposited nickel-chromium/nickel-aluminum ( $\mathrm{Ni}-\mathrm{Cr} / \mathrm{Ni}-\mathrm{Al})$ thermocouples on a metal-based blade [13]. Platinum and palladium TFTCs are extremely easily oxidized [14,15]. Ceramic materials have been used in TFTCs for their stronger oxidation resistance and stable chemical structure. The Virginia Polytechnic Institute and State University had presented tantalum carbide/titanium carbide (Ta-C/Ti-C) TFTCs by radio frequency magnetron sputtering, the film failure occurred at temperatures above $1070{ }^{\circ} \mathrm{C}$ [16]. Indium tin oxide (ITO) has a faster volatilization speed at temperatures over $1100{ }^{\circ} \mathrm{C}$ and at melting points below $1200^{\circ} \mathrm{C}$ [17]. The TFTCs reported recently can hardly work for a long time in an air environment with a temperature higher than $1400^{\circ} \mathrm{C}$. Tungsten-rhenium TFTCs show considerable promise as TFTC temperature sensors because of their high melting point (at about $2800^{\circ} \mathrm{C}$ ). However, the oxidation of tungsten-rhenium TFTCs results in Seebeck coefficient changes with increasing service temperature and time, which lead to the change of thermoelectric characteristics 
on tungsten-rhenium TFTC sensors, even resulting in failure. To measure the high temperature with low airflow interference in the engine, like F119 type fighter (about $1670{ }^{\circ} \mathrm{C}$ ), it is important to discuss the thermoelectric characteristics of tungsten-rhenium TFTCs at high temperatures and present a way to avoid the failure caused by oxidation.

A tungsten-rhenium TFTC sensor was reported in the Review of Scientific Instruments [18] by our group. In this paper, we optimized the structure, process, and added a protective coating layer to increase the service temperature to $1420^{\circ} \mathrm{C}$. Firstly, the sensor was designed by the simulation results. Secondly, $95 \mathrm{wt} \%$ tungsten $-5 \mathrm{wt} \%$ rhenium (W-5Re) and $74 \mathrm{wt} \%$ tungsten $-26 \mathrm{wt} \%$ rhenium $(\mathrm{W}-26 \mathrm{Re})$ TFTCs were fabricated by radio frequency (RF) magnetron sputtering. The TFTCs with a protective coating layer, which mainly contained aluminum oxide $\left(\mathrm{Al}_{2} \mathrm{O}_{3}\right)$, were prepared and compared with the uncoated sample. Finally, the repeatability error, electromotive force (EMF) behavior and the constant time of the carbon dioxide $\left(\mathrm{CO}_{2}\right)$ laser pulse of the TFTCs with a protective coating layer were investigated.

\section{Materials and Methods}

Equation (1) indicates the relationship between the output voltage and temperature, where $V$ is the voltage output of thermocouples, $S_{A}$ and $S_{B}$ represent the Seebeck coefficient of two kinds of materials. $T_{1}$ and $T_{2}$ represent the temperature of the cold and hot junction.

$$
\mathrm{V}=\int_{T_{1}}^{T_{2}}\left(S_{A}-S_{B}\right) T d t
$$

The Seebeck coefficient $S$ is influenced by basic physical quantities, such as the Fermi level, effective mass, relaxation time and scattering mechanism, which can be described as Equations (2) and (3) in the metal thermocouple material, when no temperature gradient exists:

$$
\begin{gathered}
S=\mp \frac{1}{e T}\left[\frac{K_{1}}{K_{2}}-E_{F}\right] \\
K_{i}=\int_{0}^{\infty} \tau U_{x}^{2} g(E) E^{i-1} \frac{\partial f_{0}}{\partial E} d E,(i=1 \sim 3)
\end{gathered}
$$

where $f_{0}$ refers to the distribution function of the carrier in the equilibrium state, $h$ refers to the characteristic parameters in the relaxation process, $E_{F}$ refers to the Fermi level, $\tau$ refers to the dielectric constant, $e$ refers to the electric charge of a single electron. Equation (4) indicates the density of the states of a carrier near the conduction band bottom:

$$
g(E)=\frac{4 \pi\left(2 m^{*}\right)^{3 / 2}}{h^{3}} E^{1 / 2}
$$

where $m *$ refers to the effective mass of the carrier, $h$ refers to the Planck constant, and $E$ refers to the energy of the carrier. The carrier is a kind of fermion, which has spin. It obeys the Pauli exclusion principle and Fermi-Dirac distribution.

In general, thermocouples are classified into two types: Metal type and semiconductor type, all based on the Seebeck effect, but the sensing mechanism is slightly different. Common semiconductor types such as ITO/In $\mathrm{O}_{3}, \mathrm{Lax}_{\mathrm{Sr}_{1-x}} \mathrm{CrO}_{3}$ (LSCO)/ITO, will form a p-n type junction. The Seebeck coefficient for both materials needs to be considered individually. However, the metal type, as discussed here, does not form a p-n type junction. The metal type works in pairs for both materials to make different free electron diffusion rates and a single Seebeck coefficient for each part, like W-5Re and $\mathrm{W}$-26Re separately, and is not usually characterized. 
Thin films were sputtered by RF magnetron sputtering (DISCOVERY, 635, Moorestown, NJ, US) from high purity $101.6 \mathrm{~mm}$ diameter W-5Re and W-26Re targets (purity 99.99\%, ZHONGNUO Co., Beijing, China) on a silicon carbide $(\mathrm{SiC})$ ceramic substrate. The structure and process are shown in Figure 1. The SiC substrates were cleaned by ultrasonic with acetone and ethyl alcohol before preparation. The films were patterned using conventional photolithography techniques. Then, the pattern was formed through a mask by UV light exposure (WJH, ABM6, San Jose, CA, US). The hot junction, which determined the thermal load, was made by the superposition film of the W-5Re film and the W-26Re film, while the voltage was outputted from the end of the negative film [19]. The wires were attached at the cold junction by the ceramic jig. We used copper $(\mathrm{Cu})$ foil to make the thermocouple cold junction electrical contacts. Argon (Ar) gas was added to the sputtering after vacuum pumping. The sputtering parameters of the $\mathrm{W}-5$ Re and $\mathrm{W}-26 \mathrm{Re}$ thin films are shown in Table 1. The TFTCs were heat-treated at $300^{\circ} \mathrm{C}$ for $6 \mathrm{~h}$ [20] in the experiment.

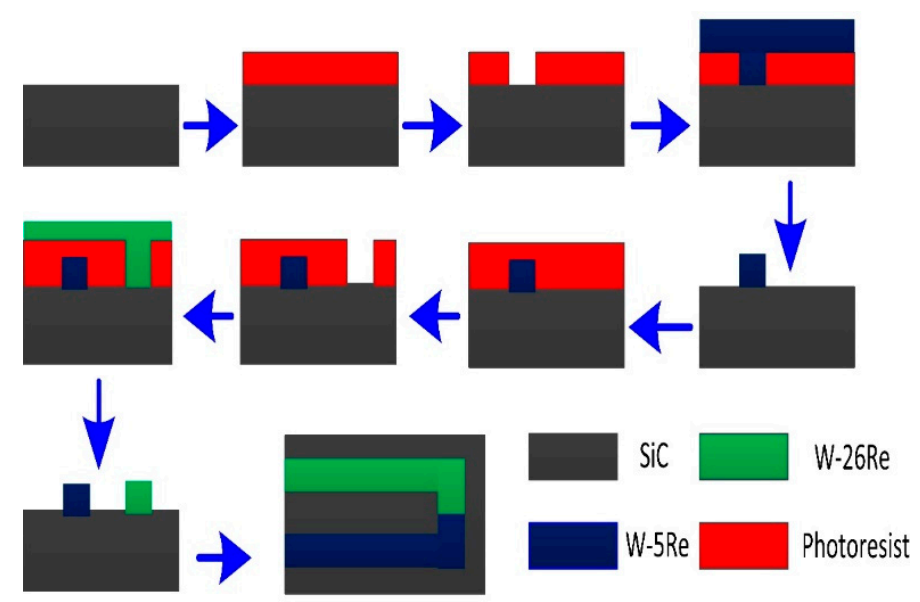

Figure 1. Brief schematic of tungsten-rhenium thin-film thermocouples (TFTCs).

Table 1. Sputtering parameters of $95 \mathrm{wt} \%$ tungsten $-5 \mathrm{wt} \%$ rhenium (W-5Re) and $74 \mathrm{wt} \%$ tungsten -26 wt $\%$ rhenium (W-26Re) thin films.

\begin{tabular}{ccc}
\hline \multirow{2}{*}{ Sputtering Parameters } & \multicolumn{2}{c}{ Targets } \\
\cline { 2 - 3 } & W-5Re & W-26Re \\
\hline Target Diameter (mm) & 101.6 & 101.6 \\
Argon Flow Rate (Sccm) & 30 & 60 \\
Sputtering Power (W) & 400 & 200 \\
Vacuum Degree (Torr) & $0.7 \times 10^{-6}$ & $1 \times 10^{-6}$ \\
\hline
\end{tabular}

A muffle furnace (Nabertherm, P300 LHT 2-17, Lilienthal, Germany) and a carbon dioxide laser generator (AL 30, ACCESSLASER, Shenzhen, China) were used to analyze the static and dynamic thermal response of the TFTCs, as shown in Figure 2. The hot junction was put in the muffle furnace. The cold junction was outside of the furnace. The S-type and K-type standard armored thermocouples (OMEGA, Norwalk, CT, US) were attached on the hot and cold junction separately to measure the temperature. The hot and cold junction temperature and the TFTC output voltage data were recorded using a data recorder (HIOKI, LR8431-30, Nagano-ke, Japan). Laser response experiments were done. A function generator (Tektronix, 2200, Shanghai, China) was used to help provide a dynamic thermal shock of the laser generator. The signal was collected by a high-frequency oscilloscope (Tektronix, MDO3012, Shanghai, China). In order to analyze film changes, the component of the TFTCs was taken by X-ray diffraction (XRD, Rigaku Corporation, d/max-2400, Beijing, China). 


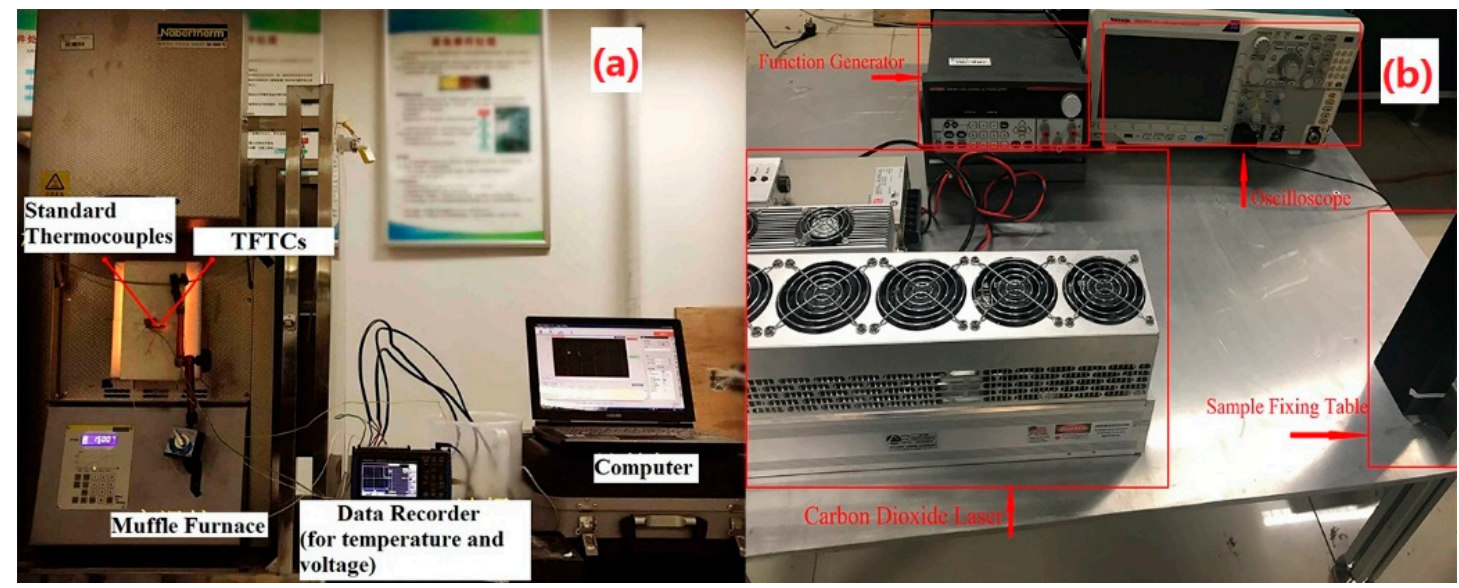

Figure 2. Static (a) and dynamic (b) high-temperature thermoelectric measurement experiment rig.

\section{Results and Discussion}

The stress finite element model was set to design the size parameters of the TFTCs [21]. In the thermal stress finite element analysis (FEA) by ANSYS (ANSYS Inc., Berkeley, CA, US), the isotropic, thermoplastic and orthotropic behavior of the material was considered. The relationship between the thermal stress and thermoelectric characteristics was analyzed, as shown in Figure 3. The thermal stress between the W-5Re and W-26Re film ranged from $74 \mathrm{MPa}$ at $400{ }^{\circ} \mathrm{C}$ to $270 \mathrm{MPa}$ at $1400^{\circ} \mathrm{C}$, which was compressive stress. The voltage of the TFTCs ranged from $12 \mathrm{mV}$ at $400{ }^{\circ} \mathrm{C}$ to $37 \mathrm{mV}$ at $1200{ }^{\circ} \mathrm{C}$ in the temperature difference. It provided detectable electrical signals with thermal stress less than the fracture limit. The substrate thickness was $2 \mathrm{~mm}$, the line width of the TFTCs was $2 \mathrm{~mm}$, the thickness of the $\mathrm{W}-5 \operatorname{Re}$ and $\mathrm{W}-26 \mathrm{Re}$ film were $2 \mu \mathrm{m}$, and the length of positive and negative parts was $8 \mathrm{~cm}$.

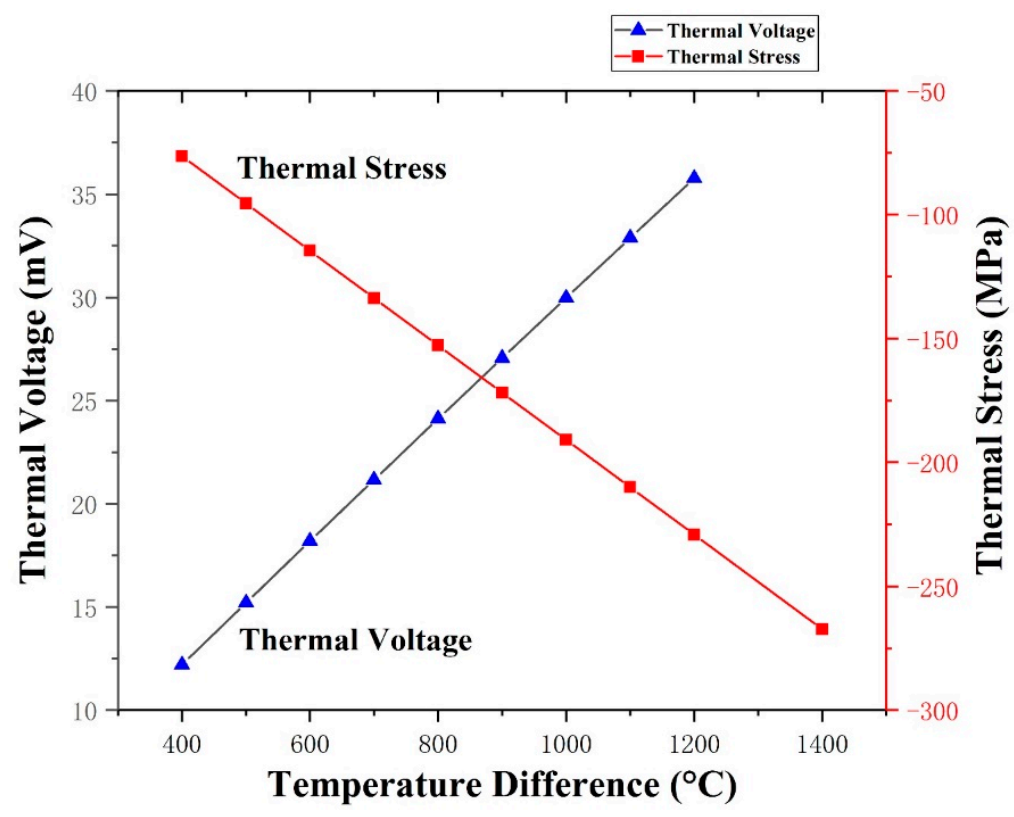

Figure 3. The relationship between thermal stress and thermoelectric characteristics by finite element analysis (FEA).

In order to analyze film changes, the sections and surface of the TFTCs were taken with a scanning electron microscope (SEM, type: Tescan Mira 3, Shanghai, China), as shown in Figure 4. 


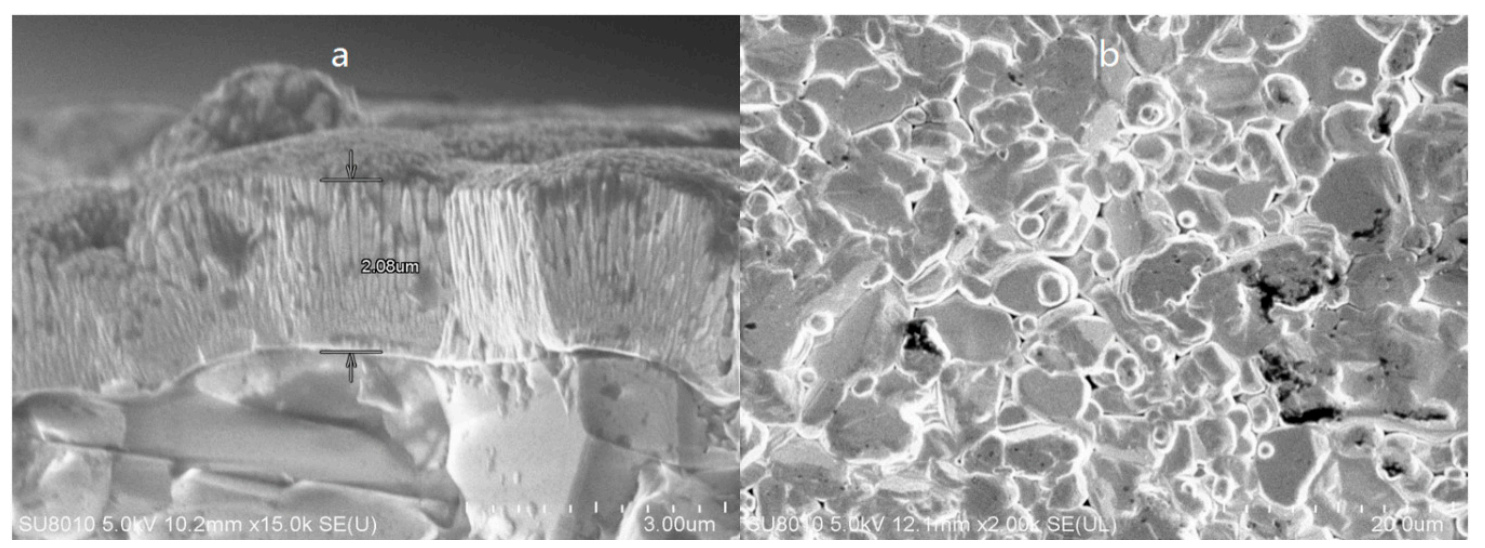

Figure 4. SEM images of the $95 \mathrm{wt} \%$ tungsten $-5 \mathrm{wt} \%$ rhenium (W-5Re) section (a) and surface (b) after heat treatment.

The post-processing instrument was designed to compensate for the cold junction temperature and record data, which is shown in Figure $5 \mathrm{c}$,d. The relationship between the Seebeck coefficient and temperature was set at the system of the post-processing instrument to realize data conversion. Considering the Seebeck coefficient changed slowly with the temperature, the mapping table of the output voltage and temperature was set in each to one degree. The post-processing instrument could be divided into two parts: The digital part and the analog part. The analog part complete the output voltage of the thermocouple acquisition and conditioning, including the analog to digital conversion circuit (ADC) and ADC drive circuit, and the chip power supply; the digital part read the ADC conversion results at the same time to get the cold injunction temperature through the temperature sensor. The temperature data was displayed. In addition, the digital part had local storage and a universal serial bus (USB) interface, which was convenient for the communication of the host computer. The TFTCs coated with the aluminum oxide $\left(\mathrm{Al}_{2} \mathrm{O}_{3}\right)$ protective coating layer were prepared by $\mathrm{RF}$ sputtering to compare with the uncoated sample. Figure 5 shows the TFTC sample, TFTC sample with the coating layer, post-processing instrument, and post-processing logic diagram.

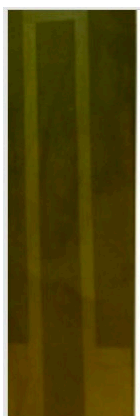

a

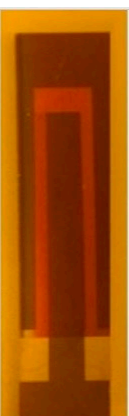

b

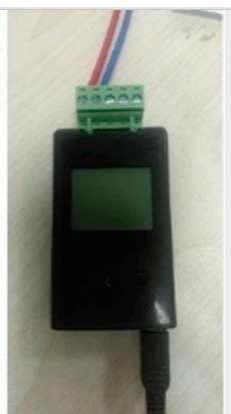

C

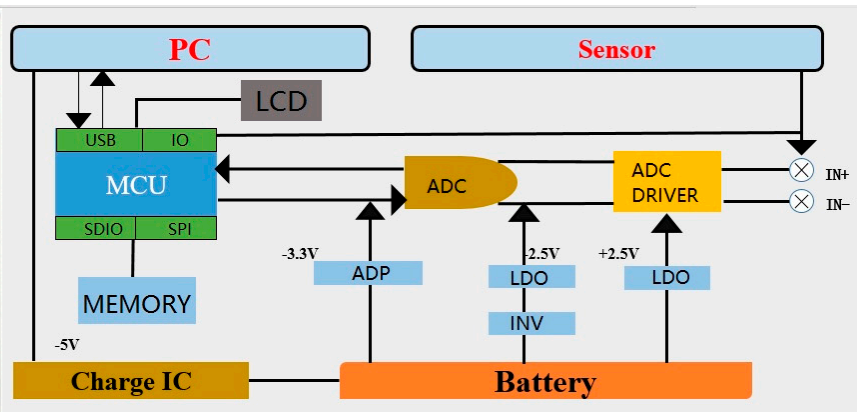

d

Figure 5. TFTCs sample (a), TFTCs sample with coating layer (b), post-processing instrument (c), post-processing logic diagram $(\mathbf{d})$.

The XRD patterns of the W-5Re and W-26Re film serviced at $0{ }^{\circ} \mathrm{C}, 600{ }^{\circ} \mathrm{C}$ and $1420{ }^{\circ} \mathrm{C}$ in air are shown in Figure $6 \mathrm{a}, \mathrm{b}$ separately to analyze the influence of oxidation on the tungsten-rhenium TFTCs. It could be observed that the film had a strong (200) preferred orientation. As the temperature increased to $600{ }^{\circ} \mathrm{C}$ for a long time, the intensity of the diffraction peak changed. The tungsten was oxidized into tungsten trioxide $\left(\mathrm{WO}_{3}\right)$ when compared with the XRD standard card (JADE card, No.72-1465), shown in Figure $6 \mathrm{c}$. It could be observed from Figure $6 \mathrm{~b}$ that the situation was approximately the same for $\mathrm{W}$-26Re. The component of the films was stable at $1420^{\circ} \mathrm{C}$ after the coating layer $\left(\mathrm{Al}_{2} \mathrm{O}_{3}\right)$ was added. The peak of the film without a coating layer at $1420^{\circ} \mathrm{C}$ still demonstrated oxidation of tungsten, 
similar to the peak at $600{ }^{\circ} \mathrm{C}$. In this experiment, the thickness of the tungsten-rhenium film in the sample was $2 \mu \mathrm{m}$ and the thickness of the $\mathrm{Al}_{2} \mathrm{O}_{3}$ coating layer was $20 \mathrm{~nm}$. Since the coating layer was very thin and with regard to transmissivity, tungsten-rhenium is a metal with high reflectivity, it was difficult to observe the peak of the coating layer on it. In addition, here we focused on the oxidation of W-5Re and W-26Re, the peak of $\mathrm{Al}_{2} \mathrm{O}_{3}$ was not an important point of observation for its high thermal stability. The SEM (Tescan Mira 3, Shanghai, China) section image of W-5Re and W-26Re with a coating layer is shown in Figure $6 \mathrm{~d}$. The coating layer was dense, which could help to avoid oxidation of the TFTCs. The porosity of the coating layer may lead the uncoated part of the film to become oxidized and determines the stability of the TFTCs. It was hard to control the density, which requires adjustment of the preparation process for the coating layer. This, however, is not the focal point of this article. A four-probe conductivity tester (ST2258C, Suzhou Jingge Electronic Co., Suzhou, China) was used to test the electrical conductivity changes during the service. The conductivity of $\mathrm{W}-5 \mathrm{Re}$ changed from $10.83 \mathrm{~S} / \mathrm{m}$ at room temperature to $0.018 \mathrm{~S} / \mathrm{m}$ at $600{ }^{\circ} \mathrm{C}$ after four hours. The conductivity of W-5Re at $1420^{\circ} \mathrm{C}$ with a coating layer and without a coating layer was $8.62 \mathrm{~S} / \mathrm{m}$ and $0.003 \mathrm{~S} / \mathrm{m}$, respectively. The conductivity was measured at room temperature after heating, which was limited by the service temperature of the four-probe conductivity tester. The electrical conductivity reduced by nearly 1000 times in the oxidation process, which obeyed the oxidation phenomena in the XRD results. The oxidation temperature of rhenium was relatively high. It began at $1500{ }^{\circ} \mathrm{C}$ and the relative content was small in this case. It was a secondary factor in this. This paper focuses on the oxidation of tungsten. It can be observed that the thermosensitive part composed of W-5Re and W-26Re film was oxidized at a high temperature and a coating layer process could avoid the TFTCs from being oxidized.

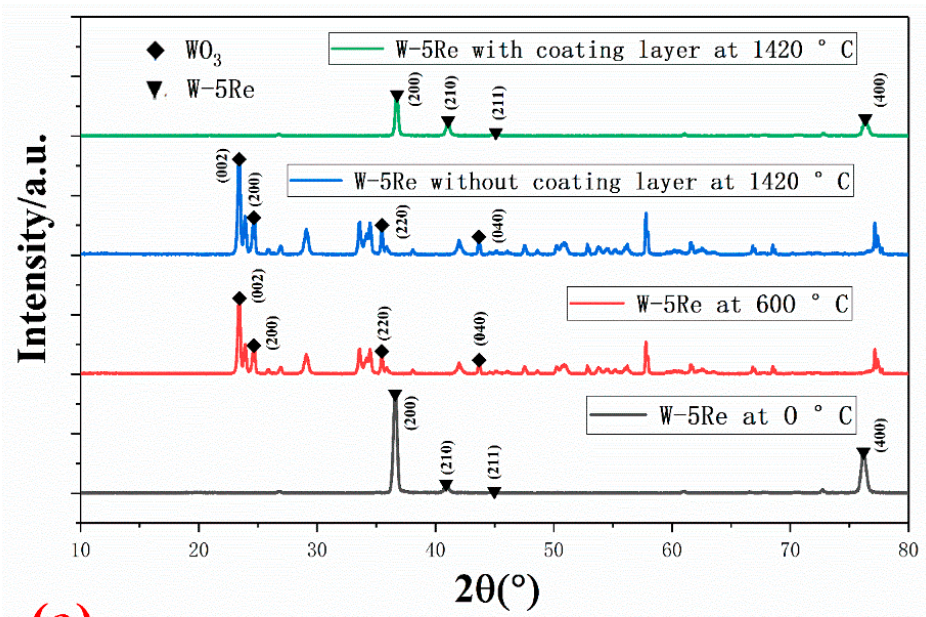

(a)

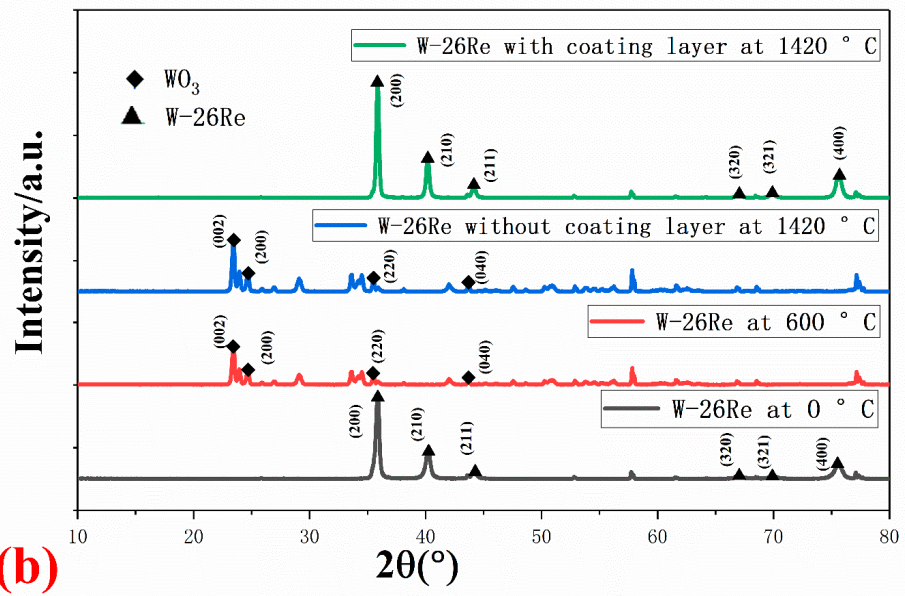

Figure 6. Cont. 
(c)

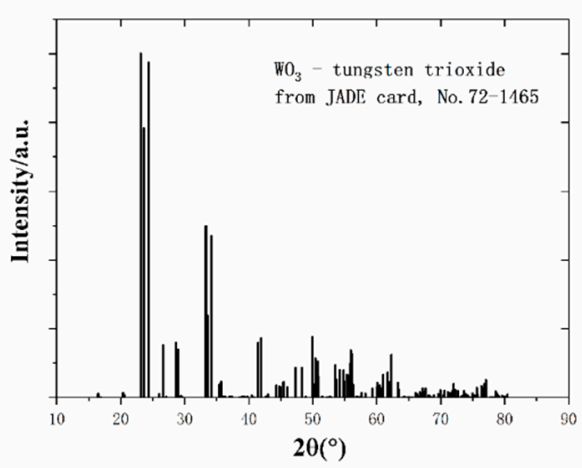

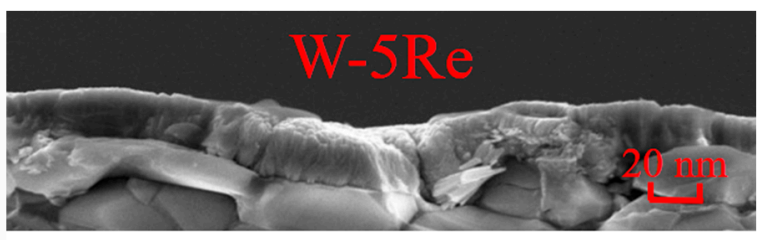

(d)

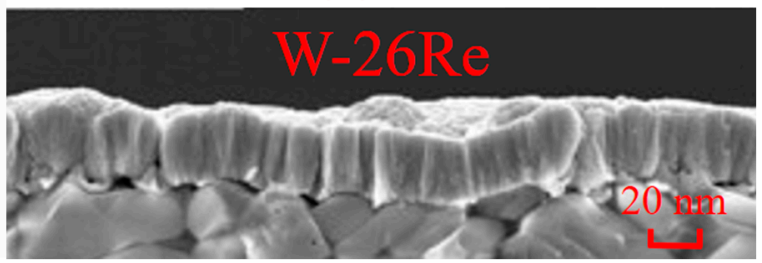

Figure 6. XRD patterns of W-5Re (a) and W-26Re thin-film and coated thin-film at different temperatures (b), XRD standard card (c) of $\mathrm{WO}_{3}$, and SEM section image (d) of W-5Re with coating layer.

The oxidation and compositional changes of the tungsten-rhenium TFTC ultimately affect the thermoelectric properties, including the Seebeck coefficient and repeatability error, and lead to the failure of TFTCs, which is shown in Figure 7a. A coating layer process can not only avoid the TFTCs from being oxidized but ensure its Seebeck effect to yield a thermoelectric voltage at $1420{ }^{\circ} \mathrm{C}$, which is shown in Figure $7 \mathrm{~b}$.

In Figure $7 \mathrm{a}$, a series of output voltages were collected for the heating process of the tungsten-rhenium TFTCs. The two curves had a similar linear shape, while the tungsten-rhenium with the coating layer had a better linear relationship with temperature difference. In addition, for the uncoated TFTC, it had a higher output voltage than that of the coated sample. This was due to the reduction of the hot junction temperature caused by the heat insulation effect of the coating layer. When the tungsten-rhenium TFTCs suffered from a higher temperature, up to nearly $600{ }^{\circ} \mathrm{C}$ for a long time (Figure 7a), the uncoated TFTCs failed after a long time of service because of oxidation. Therefore, the coating layer could enhance the high-temperature performance of the tungsten-rhenium TFTCs prominently. The repeatability of the TFTCs was tested in three cycles, as shown in Figure $7 \mathrm{~b}$. The TFTCs tracked with the hot junction temperature very well. There were no failures of the TFTCs up to $1420^{\circ} \mathrm{C}$. Therefore, tungsten-rhenium TFTCs with an $\mathrm{Al}_{2} \mathrm{O}_{3}$ coating layer are promising thermal sensors for high-temperature sensing.

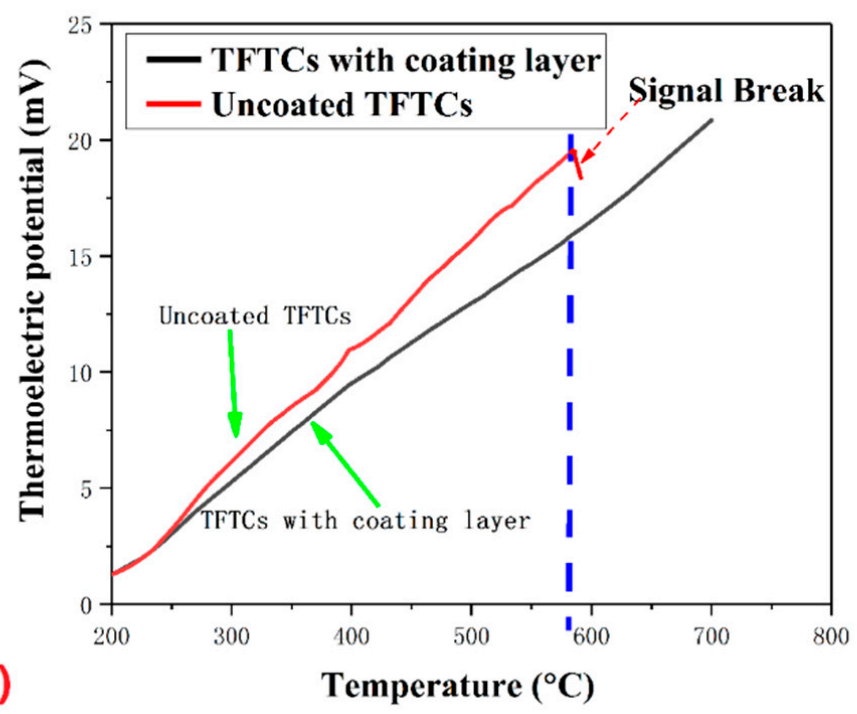

Figure 7. Cont. 


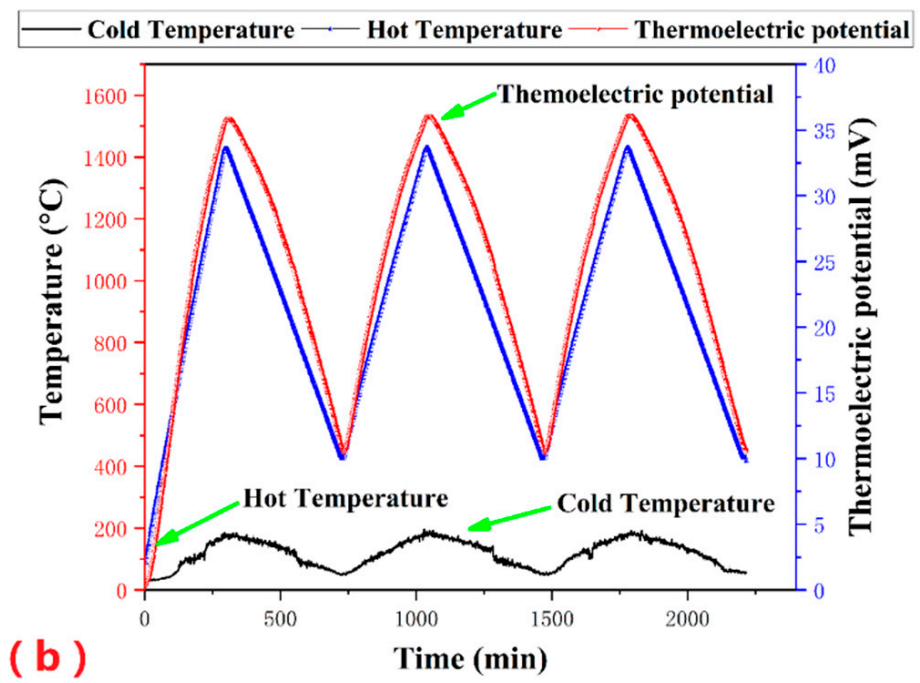

Figure 7. Thermoelectric output of tungsten-rhenium TFTCs in heating at $700{ }^{\circ} \mathrm{C}(\mathbf{a})$, and in cycle of heating and cooling with a peak hot junction temperature of $1420^{\circ} \mathrm{C}(\mathbf{b})$.

The maximum standard deviation of the three cycles was $1.048 \mathrm{mV}$. The repeatability error of the coated tungsten-rhenium TFTCs was $\pm 4.1 \%$. The peak thermoelectric voltage of the TFTCs with protection was $35.51 \mathrm{mV}$ when the temperature difference between the hot junction and cold junction was $1240{ }^{\circ} \mathrm{C}$ (the hot junction temperature was $1420^{\circ} \mathrm{C}$ ). The average Seebeck coefficient at $1240{ }^{\circ} \mathrm{C}$ reached $28.63 \mu \mathrm{V} /{ }^{\circ} \mathrm{C}, 27 \%$ larger than the average Seebeck coefficient of the standard C-type (tungsten-rhenium, $22.51 \mu \mathrm{V} /{ }^{\circ} \mathrm{C}$ at $1240{ }^{\circ} \mathrm{C}$ [22]) thermocouple at $1240{ }^{\circ} \mathrm{C}$ for the component difference in RF magnetron sputtering between the metal wire and film. The Seebeck effect is influenced by basic physical quantities, such as the Fermi level, effective mass, relaxation time, scattering mechanism and carrier density. The standard C-type was made of tungsten-rhenium alloy wire. These physical quantities may be changed by magnetron sputtering of tungsten-rhenium compared with the wire due to the size effect [23].

Equation (5) is used to describe the EMF behavior:

$$
E\left(T^{*}\right)=A \times\left(T^{*}\right)^{2}+B \times\left(T^{*}\right)+C
$$

Here $T^{*}$ refers to the temperature difference between the hot junction and cold junction; the unit of $T^{*}$ is ${ }^{\circ} \mathrm{C}$. V refers to the output voltage; the unit of $\mathrm{E}$ is $\mathrm{mV}$. The $R^{2}$ values for the fittings were 0.9992. The parameter $C$ was arbitrarily set to zero as the boundary condition. $T^{*}=0$ must be satisfied in the EMF behavior formula to facilitate the practical application. The results are shown in Table 2. In addition, the constant time of the coated TFTCs and uncoated TFTCs was tested. We measured a 95\% response time of about $0.9 \mathrm{~ms}$ and $0.36 \mathrm{~ms}$, respectively. This showed the influence of the coating layer on heat transfer and the response was very small. Compared with the response time of the armored thermocouple wire (about $1 \mathrm{~s}$ ), the tungsten-rhenium TFTCs showed a great application prospect to meet the requirements of fast response measurements.

Table 2. Polynomials coefficients of the TFTCs.

\begin{tabular}{ccccc}
\hline $\mathbf{A}\left(\mathbf{m V} /{ }^{\circ} \mathbf{C}^{2}\right)$ & $\mathbf{B}\left(\mathbf{m V} /{ }^{\circ} \mathbf{C}\right)$ & $\mathbf{C}(\mathbf{m V})$ & $\begin{array}{c}\text { Average Seebeck } \\
\text { Coefficient } \\
\text { at } \mathbf{1 2 4 0}{ }^{\circ} \mathbf{C}\left(\mu \mathrm{V} /{ }^{\circ} \mathrm{C}\right)\end{array}$ & $\begin{array}{c}\text { Average Seebeck } \\
\text { Coefficient of Standard } \\
\text { C-type Thermocouple } \\
\mathbf{1 2 4 0}{ }^{\circ} \mathbf{C}\left(\mu \mathrm{V} /{ }^{\circ} \mathbf{C}\right)\end{array}$ \\
\hline $\begin{array}{c}-0.8627 \times \\
10^{-6}\end{array}$ & 0.03084 & 0 & 28.63 & 22.51 \\
\hline
\end{tabular}


The thickness of the $\mathrm{Al}_{2} \mathrm{O}_{3}$ coating layer here was $500 \mathrm{~nm}$. We tested the coating layers with different thicknesses to optimize the thermoelectric response. The Seebeck coefficient was $28.63 \mu \mathrm{V} /{ }^{\circ} \mathrm{C}$, $28.56 \mu \mathrm{V} /{ }^{\circ} \mathrm{C}, 28.53 \mu \mathrm{V} /{ }^{\circ} \mathrm{C}$ when the thickness of the $\mathrm{Al}_{2} \mathrm{O}_{3}$ coating layer was $500 \mathrm{~nm}, 1 \mu \mathrm{m}$ and $2 \mu \mathrm{m}$, respectively. It could be observed that the thermoelectric characteristics did not change with the thickness of the $\mathrm{Al}_{2} \mathrm{O}_{3}$ coating layer. The thermoelectric characteristics were determined by tungsten-rhenium, not by the influence of the protective layer due to the Seebeck effect.

The TFTCs exhibited repeatability at the test temperature. In the third heat cycle, the maximum output voltage of the thermocouple dropped by $0.3 \mathrm{mV}$, which may be due to additional annealing effects and volatilization in the heating cycles. The drift rate $\varepsilon$ was set to indicate the stable service time of the TFTCs, as shown in Equation (6):

$$
\varepsilon(T)=\frac{\Delta V(T)}{\operatorname{Vref}(T)} \cdot \frac{T}{\Delta t}
$$

Here $\Delta V(T)$ is the voltage drop, $\operatorname{Vref}(T)$ is the initial thermoelectric voltage and $\Delta t$ is the lifetime during which the thermocouple soaked at a particular temperature $T$ for the hot junction. The optimized TFTCs were heated at $1420^{\circ} \mathrm{C}$ for $10 \mathrm{~h}$ to test the drift rate. The drift rate was $9.6^{\circ} \mathrm{C} / \mathrm{h}$. Compared with the tungsten-rhenium TFTCs we presented before, the highest stability service temperature increased to $1420{ }^{\circ} \mathrm{C}$ and the stable service time increased from $2 \mathrm{~h}$ to $10 \mathrm{~h}$. Compared with the current TFTCs, such as ITO 90/10 vs. $\mathrm{In}_{2} \mathrm{O}_{3}$, which has a peak voltage at $1200{ }^{\circ} \mathrm{C}$ for the hot junction temperature and a drift rate of $24.06^{\circ} \mathrm{C} / \mathrm{h}$ [24], or the traditional Type-K armored thermocouple in air [25], this tungsten-rhenium TFTCs sensor provided better performance during in situ and real-time temperature measurements at $1420^{\circ} \mathrm{C}$ for a long time.

\section{Conclusions}

A silicon carbide ceramics-based tungsten-rhenium TFTC sensor was prepared by RF sputtering. The TFTCs coated with an $\mathrm{Al}_{2} \mathrm{O}_{3}$ layer were prepared and compared with the uncoated sample. The experiment showed the coating layer avoided the failure of the TFTCs, caused by oxidation at nearly $600{ }^{\circ} \mathrm{C}$ effectively and increased the stable maximum service temperature to $1420^{\circ} \mathrm{C}$ when the cold junction temperature was kept at $0{ }^{\circ} \mathrm{C}$. The average Seebeck coefficient at $1240{ }^{\circ} \mathrm{C}$ reached $28.63 \mu \mathrm{V} /{ }^{\circ} \mathrm{C}$, which was $27 \%$ larger than the average Seebeck coefficient of the standard C-type. The repeatability error was $\pm 4.1 \%$ and the drift rate was $9.6^{\circ} \mathrm{C} / \mathrm{h}$ for $10 \mathrm{~h}$. This solved the problem that conventional thin film thermocouples cannot directly work at a high temperature of $1420^{\circ} \mathrm{C}$ for a long time. The coated tungsten-rhenium TFTCs provide application value for high-temperature sensing in air.

Author Contributions: Conceptualization, Z.Z. and B.T.; Data curation, D.Z.; Funding acquisition, Q.L.; Software, Y.L.; Supervision, Z.J.

Funding: This work was supported by the National Key Basic Research Program of China (973, No. 2015CB057402), National Natural Science Foundation of China (No. 91748207, No. 51720105016), Shaanxi Natural Science Basic Research Project-Youth Talent Project (2016JQ5088), and Research on Intelligent Extruder Settlement Monitoring System (China Heavy Machinery Research Institute Co., Ltd., No. 20170521). Z.Z. received a China Scholarship Council fund (No. 201806280150) for his research stay at RWTH Aachen University.

Acknowledgments: In this section you can acknowledge any support given which is not covered by the author contribution or funding sections. This may include administrative and technical support, or donations in kind (e.g., materials used for experiments).

Conflicts of Interest: The authors declare no conflict of interest. The funders had no role in the design of the study; in the collection, analyses, or interpretation of data; in the writing of the manuscript, or in the decision to publish the results. 


\section{References}

1. Scervinia, M.; Rae, C. An Improved Nickel Based MIMS Thermocouple for High Temperature Gas Turbine Applications. J. Eng. Gas Turbines Power 2013, 135, 091601. [CrossRef]

2. Hackemann, P. Method for Measuring Rapidly Changing Surface Temperatures and Its Application to Gun Barrels. Theor. Res. Transl. 1964, 1, 46.

3. Holanda, R.; Anderson, R.C.; Liebert, C.H. Heat Flux Measurements on Ceramics with Thin Film Thermocouples. In Proceedings of the Structural Testing Technology at High Temperature-II, Ojai, CA, USA, 8-10 November 1993; pp. 78-87.

4. Martin, L.C.; Wrbanek, J.D. Thin film sensors for surface measurement. In Proceedings of the ICIASF 2001 Record, 19th International Congress on Instrumentation in Aerospace Simulation Facilities (Cat. No.01CH37215), Cleveland, OH, USA, 27-30 August 2001; pp. 196-203.

5. Wrbanek, J.D.; Fralick, G.C.; Farmer, S.C.; Sayir, A.; Blaha, C.; Gonzalez, J. Development of thin film ceramic thermocouples for high temperature environments. In Proceedings of the 40th AIAA/ASME/SAE/ASEE Joint Propulsion Conference and Exhibit, Fort Lauderdale, FL, USA, 11-14 July 2004.

6. Aloysius, F.H.; Walter, S.K. Thin-film sensors for space propulsion technology. In Structural Integrity and Durability of Reusable Space Propulsion Systems; National Aeronautics and Space Administration Lewis Research Center: Cleveland, OH, USA, 1989; pp. 123-126.

7. Lei, J.F.; Will, H.A. Thin-film thermocouples and strain-gauge technologies for engine applications. Sens. Actuat. 1998, 65, 187-193. [CrossRef]

8. Bastia, A.; Obikawaa, T.; Shinozukab, J. Tools with built-in thin film thermocouple sensors for monitoring cutting temperature. Int. J. Mach. Tool Manuf. 2007, 47, 793-798. [CrossRef]

9. Tougas, I.M.; Amani, M.; Gregory, O.J. Metallic and Ceramic Thin Film Thermocouples for Gas Turbine Engines. Sensors 2013, 13, 15324-15347. [CrossRef] [PubMed]

10. Zhao, Y.S.; Yang, L.H. Research progress of thin film thermocouple temperature sensor. Transducer Microsyst. Technol. 2012, 31. [CrossRef]

11. Peng, X.L.; Clyne, T.W. Mechanical stability of DLC films on metallic substrates Part II-Interfacial toughness, debonding and blistering. Thin Solid Films 1998, 312, 219-227. [CrossRef]

12. Jehn, H. High temperature behaviour of platinum group metals in oxidizing atmospheres. J. Less Common Met. 1984, 100, 321-339. [CrossRef]

13. Kreider, G.K. High Temperature Silicide Thin-Film Thermocouples. MRS Proc. 2011. [CrossRef]

14. Grant, H.P.; Przybyszewski, J.S.; Claing, R.G. Turbine Blade Temperature Measurements Using Thin Film Temperature Sensors. NASA-CR-165201. Available online: https://ntrs.nasa.gov/archive/nasa/casi.ntrs.nasa. gov/19810010750.pdf (accessed on 19 June 2019).

15. Klaus, E. Magnetron sputtering of transparent conductive zinc oxide: Relation between the sputtering parameters and the electronic properties. J. Phys. D Appl. Phys. 2000. [CrossRef]

16. Bhatt, H.D.; Vedula, R.; Desu, S.B. Thin film TiC/TaC thermcouples. Thin Solid Films 1999, 342, $214-220$. [CrossRef]

17. Liu, Y.; Ren, W.; Shi, P. Preparation and thermal volatility characteristics of In2O3/ITO thin film thermocouple by RF magnetron sputtering. AIP Adv. 2017, 7, 115025. [CrossRef]

18. Tian, B.; Zhang, Z.; Shi, P. Tungsten-rhenium thin film thermocouples for SiC-based ceramic matrix composites. Rev. Sci. Instrum. 2017, 88, 015007. [CrossRef] [PubMed]

19. Zhang, Z.K.; Tian, B.; Yu, Q.; Lin, Q.; Zhao, N.; Jing, W.; Jiang, Z. Mechanical properties analysis and process optimization for tungsten-rhenium thin film thermocouples sensor. IEEE Sens. 2017. [CrossRef]

20. Zhang, Z.K.; Tian, B.; Du, Z.; Lin, Q.; Shi, P.; Ren, W.; Zhao, N.; Jiang, Z. Effect of heat treatment on thermoelectric properties of tungsten-rhenium thin-film thermocouples by RF magnetron sputtering. AIP Adv. 2018, 8, 125113. [CrossRef]

21. Zhang, Z.K.; Tian, B.; Yu, Q.; Shi, P.; Lin, Q.; Zhao, N.; Jing, W.; Jiang, Z. Range Analysis of Thermal Stress and Optimal Design for Tungsten-Rhenium Thin Film Thermocouples Based on Ceramic Substrates. Sensors 2017, 17, 857. [CrossRef] [PubMed]

22. Tungsten-Rhenium Thermocouple Wires and Temperature-Electromotive Force (EMF) Tables; ASTM E696-95; Economic Science Press: Beijing, China, 2008; ISBN 151117062. 
23. Zhang, Z.K.; Tian, B.; Du, Z.; Lin, Q.; Zhao, N.; Jiang, Z. Impact of Magnetron Sputtering Parameters on Thermoelectric Properties of Tungsten-Rhenium Thin-Film Thermocouples Sensor. IEEE Sens. J. 2018, 18, 9896-9901. [CrossRef]

24. Zhu, W.Z.; Deevi, S.C. Development of Interconnect Materials for Solid Oxide Fuel Cells. Mater. Sci. Eng. A 2003, 348, 227-243. [CrossRef]

25. Sloneker, K.C. Life Expectancy Study of Small Diameter Type E, K, and N Mineral-Insulated Thermocouples Above $1000^{\circ} \mathrm{C}$ in Air. Int. J. Thermophys. 2011, 32, 537-547. [CrossRef]

(C) 2019 by the authors. Licensee MDPI, Basel, Switzerland. This article is an open access article distributed under the terms and conditions of the Creative Commons Attribution (CC BY) license (http://creativecommons.org/licenses/by/4.0/). 